\title{
Vulnerability scenarios appraisal in a rapid urbanising region using linguistically aggregated method
}

\author{
Nasim Yeganeh \\ MSc graduate, Department of Urban and Regional Planning, \\ Faculty of Built Environment, Universiti Teknologi Malaysia, Johor, Malaysia. \\ Email: nasim.yeganeh@gmail.com \\ Phone: +989126583920. \\ Soheil Sabri* \\ Research fellow, Centre for SDIs and Land Administration, \\ The University of Melbourne, Victoria, Australia. \\ Email: soheil.sabri@unimelb.edu.au \\ Phone: +61383446771
}

\begin{abstract}
This paper examines the application of a parameterised Ordered Weighted Average (OWA), to evaluate the risk of flood hazard. OWA generates linguistic fuzzy operations that develop a series of multi-criteria combination rules enabling a realistic strategic planning and decision making. Additionally, this research aimed to initiate appropriate planning strategies towards a resilient city. As such, the OWA method is operated in a Geographic Information Systems (GIS) environment to evaluate the spatial risk of floods in Iskandar Malaysia. The combination of current physical and social characteristics as well as future development plans (2025), have been evaluated by the means of different pessimistic and optimistic scenarios through adopting OWA. The results indicate that future developments are likely to increase the vulnerability of region. In particular, the cities and provisioned population growth areas have a higher risk level. Finally, the suggested methodology proved to be a reliable approach for strategic planning of resilient cities.
\end{abstract}

Keywords - Environmental planning, Order Weighted Average (OWA), multi-criteria evaluation, GIS, Iskandar Malaysia

\section{Introduction}

Cities worldwide are becoming more and more complex from physical, social, and economic aspects which are highly interdependent. This makes them more vulnerable to disasters, and in particular, natural disasters (Desouza \& Flanery, 2013; Dorasamy, Raman, \& Kaliannan, 2013; Godschalk, 2003). According to the United Nation's annual report flood is considered as one of the most devastating hazards worldwide. This figure is predicted to reach as high as US\$415 billion by 2030 (UNSIDR, 2015). This is more critical in regions with rapidly growing cities with the lack of appropriate planning and proactive initiatives. In 2014, over 6,000 deaths occurred because of natural disasters. More than half of these disasters took place in Asia and the pacific region (UNISDR, 2014). Simultaneously, during the last decades, flood phenomenon and it's socio-economic consequences increases globally in terms of intensity and frequency. Nearly half of the all victims of natural hazards suffer from flood and it is projected that the flood loses is reached to US\$ 60 billion by 2050 (Hartnett \& Nash, 2017; Mendoza-tinoco, Guan, Zeng, Xia, \& Serrano, 2017; Röthlisberger, Zischg, \& Keiler, 2017; Yeganeh \& Sabri, 2014).

As such, cities are always looking for initiatives that can improve its resiliency to natural hazards, effectively resist, accommodate, and recover from the effects of hazards (Röthlisberger et al. 2017).

Several tools and methodologies have been developed to evaluate the vulnerability aspects of communities and foster future planning to measure the resilience of developments (Desouza \& Flanery, 2013; Chen et al., 2019). For example, studies include urban flood and earthquake hazard zoning (Röthlisberger et al. 2017; Fernández \& Lutz 2010), modelling and risk assessment (Lawal et al. 2014; Paquette \& Lowry 2012), and vulnerability assessment (Jeffers, 2013; Yeganeh \& Sabri, 2014; Chen et al., 2019). Most of these studies leveraged spatial analysis enabled tools (i.e. ESRI's ArcGIS, TerrSet, QGIS) integrated with uncertainty modelling methods (Fuzzy logic, Neural Network, Multi-Criteria Decision Analysis (MCDA)) (Yeganeh \& Sabri 2014; Fernández \& Lutz 2010). One of more common methods, Weighted Linear Combination (WLC) is a technique that integrates MCDA and Geographic Information Systems (GIS) to scientifically evaluate risks and vulnerabilities (Lawal et al. 2014; Yeganeh \& Sabri 2014; Chowdhury \& Al-Zahrani 2014). Since modelling and assessments are complicated, decision makers need more accurate models and scenarios to develop the appropriate 
strategies. To date, not many studies have been conducted on incorporating the fuzzy methods such as ordered weighted average (OWA) with spatial analysis and models for risk assessment and vulnerability evaluation. Many scholars hold this view that OWA is a holistic approach and is able to facilitate optimistic, pessimistic and trade-off scenarios. OWA generates an extensive variation of decision alternatives to address uncertainty affiliated with the interplay between various criteria in complex phenomenon (Drobne \& Lisec, 2009; Ferretti \& Pomarico, 2013; Gorsevski, Donevska, Mitrovski, \& Frizado, 2012; Malczewski, 2006; Malczewski et al., 2003). As such, this study aims to develop a flood vulnerability assessment methodology using OWA integrated with GIS in order to aid accurate decision making for urban resilience measures.

The study is conducted in Iskandar Malaysia as a rapidly urbanising region. In order to indicate the effectiveness of the new methodological framework, the results of this study are compared with the WLC-GIS method which was previously conducted in the same region (Yeganeh \& Sabri, 2014).

The next section defines the risk, hazard, and vulnerability in the urban resilience context and summarises the literature on urban resilience, natural hazards, vulnerability assessment and the methods that have been used so far to conceptualise the methodology of this study. The third section, "methodology", describes the methods that were used to develop the model. This is followed by the section "results and discussion" which explains the outcomes and compares them with similar studies. Ultimately, the paper is concluded by summarising the findings and their implications in urban resilience and vulnerability. The conclusion section also suggests future research recommendation in urban resilience and other supportive methodologies.

\section{Risk, hazard, and vulnerability in the context of urban resilience}

The literature on risk describes it as the probability of an undesirable occurrence among vulnerable subjects (Isunju et al. 2016; Brooks 2003).Therefore, risk is described as a function of disaster, vulnerability factors and adaptive capacity. The interplay between the factors are complex but is been simplistically demonstrated in the following equation:

$$
\text { Risk }=\text { Hazard } * \text { Vulnerability/Capacity }
$$

In fact, "hazard" indicates a threatening occurrence or potentially damaging phenomenon. Vulnerability is defined as the situations determined by physical, environmental and socio-economic features or processes that expand the susceptibility of a society to the effects of disasters (Isunju et al. 2016). Vulnerability is not only indexed by hazards exposure, it also interconnects with the resilience of the system under threat of hazard (Berkes, 2007). Resilience and vulnerability are two related concepts that have gained currency in various types of disaster-related discourses (Usamah, Handmer, Mitchell, \& Ahmed, 2014).

\section{a. What is a resilient city?}

Urban entities can be broken down into physical and social components. During disasters physical system must be capable of remaining functional or regaining. As such, the physical features of the city should be wellorganised to mitigate the impact of hazards. Aside from physical system, human communities are recognised as a city's social and institutional components. Community networks must be capable of tolerating extraordinary situations. The physical and social components of the city must be considered as the major drives in identifying the city indicators for adopting risk and vulnerability evaluation methodology (Malalgoda et al. 2014; Desouza \& Flanery 2013; Godschalk 2003).

City resilience expresses the capability of all aspects of an urban system, temporally and spatially to endure, adapt to and recover from the influences of a disaster in a well-timed and effective ways (Harrison \& Williams 2016; Isunju et al. 2016; UNISDR 2016).

Generally, increased population density causes pressure on land, resources, and ecosystems. Thus interrelationships between involved factors have to be investigated (Gangrade et al., 2019; Chelleri, Waters, Olazabal, \& Minucci, 2015; Malalgoda, Amaratunga, \& Haigh, 2014). The key challenge therefore is to identify reliable indicators and analysis methods that will give planners and decision makers a greater understanding.

\section{b. Hazard mitigation}

Hazard mitigation is recognised as actions that reduce or omit the risk and long term effects of hazards and consists of a wide range of measures. Urban disaster reduction is considered as a complex process of disaster reduction process and its main aim is to establish resilient cities (Desouza \& Flanery, 2013; Godschalk, 2003; Kulawiak \& Lubniewski, 2013).

\section{c. Hazard risk evaluation and vulnerability assessment methods}

Several studies have adopted the integration of multi-criteria analysis (MCA) such as Analytic Hierarchy Process (AHP) and Analytic Network Process (ANP) with GIS to incorporate uncertain factors in flood risk management (Lawal et al. 2014; Levy \& Hall 2005). In fact, MCA presents techniques and procedures for analysing complicated decision issues which often include incommensurable data or indicators (Fernández \& Lutz 2010). Most of these studies (Fernández \& Lutz 2010; Lawal et al. 2014) utilised WLC for developing the models. In WLC methods, risk neutrality is considered to be the best solution for the problem; it is assumed that 
the best result can be obtained only with assigned criterion weight. However, there are fundamental limitations in this method when it comes to the decision making process. These limitations are explained by (Jiang, Eastman, \& Eastman, 2000) as follows:

- The first issue in utilising WLC is that the various aggregation techniques utilised in developing decision.

- The second issue is related to the standardisation of factors. Rescaling the range according to an ordinary numerical ground by simple linear transformation is considered to be the most typical approach to the problem.

- The third issue related to risk related decision making is the likelihood that the decision would be inappropriate. Continuous criteria of WLC would emerge in order to indicate a further uncertainty which is not smoothly calculated by stochastic methods.

Each of the WLC standardised factors indicate suitability; the higher the value, the more appropriate the location for development. In complex and multi-criteria issues, excluding some locations and considering them as areas with no vulnerability may put a group of people in jeopardy. Thus, it is crucial to utilise methods that address these issues.

One of the methods that can be used to overcome these computation issues is the ordered weighted averaging (OWA) approach that was developed by (Yager, 1988). This is a generalisation of the Boolean overlay and the WLC method. This method provides an entire range of decision making strategy spaced along the primary dimensions of the trade-off degree among the criteria included the degree of risk in the solution. Figure 1 indicates the decision-making strategy space where $\mathrm{x}$-axis demonstrates a continuum from maximum risk to no risk, and the y-axis demonstrates a continuum from no trade-off to maximum trade-off. In general, the OWA approach is utilised to generate an extensive range of decision options to address uncertainty linked with multicriteria interactions (Liao et al., 2017; Ferretti \& Pomarico, 2013; Malczewski et al., 2003). Following the definition of risk presented earlier, by using OWA, it is possible to generate several decision scenarios that considers the mitigation of different risks. In decision-making pertinent to urban and regional planning, OWA is being utilised for watershed management strategies (Malczewski et al., 2003), landfill site selection, and land suitability analysis (Gorsevski et al., 2012; Malczewski, 2006). However, there is a lack of OWA method application in developing and evaluating flood risk scenarios using indicators directly related to vulnerability while the flood hazard influence people's life. Iskandar Malaysia as the study area, has been affected by flood several times. Therefore, using OWA as a decision making strategies can be utilised to offer a continuous range of decision strategies to help planner and decision maker for supporting the inhabitants with an appropriate planning towards resilience city.

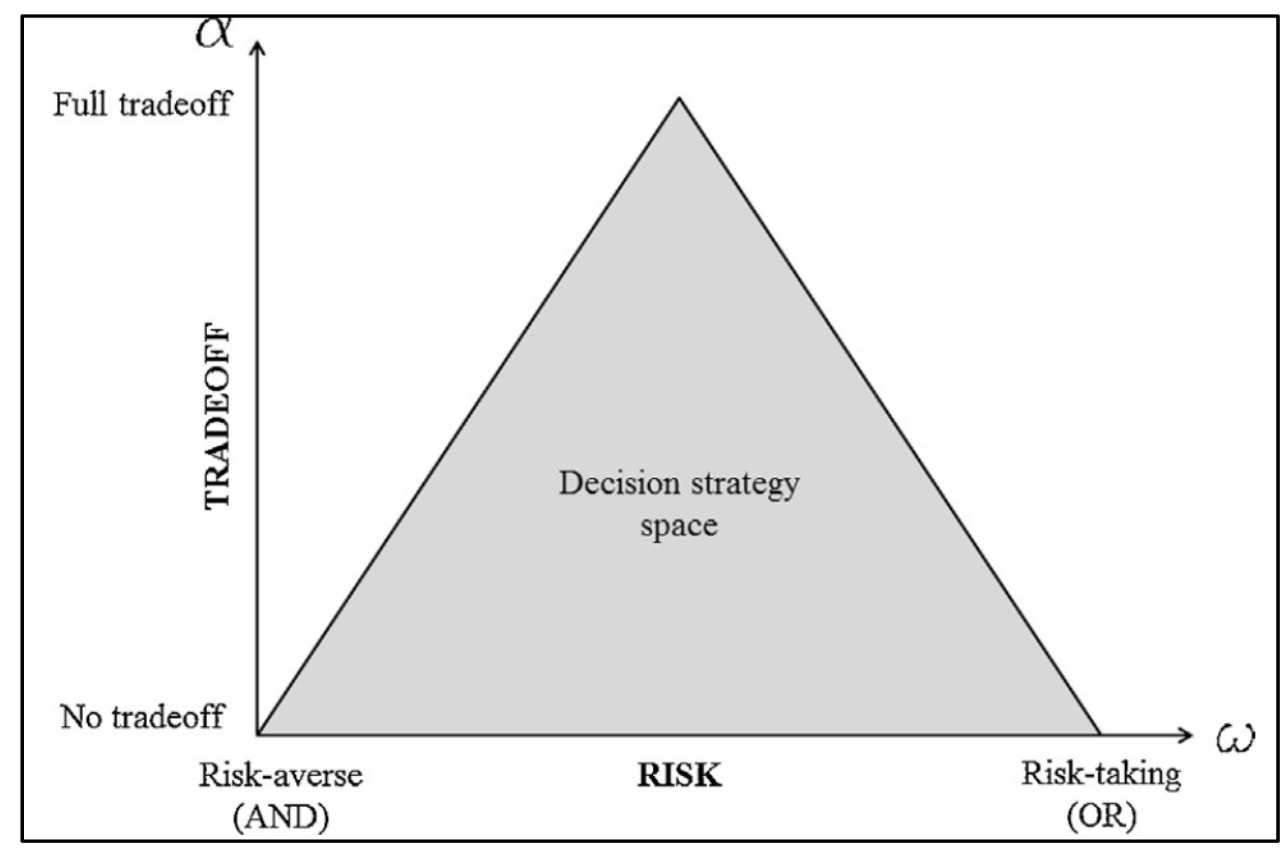

Figure 1. Decision strategy space in OWA. Adopted from (Ferretti \& Pomarico, 2013). 


\section{Methodology}

\section{a. Ordered Weighted Average approach}

OWA is regarded as a method for criteria ranking and inscribing the uncertainty from their interaction (Gorsevski et al., 2012; Liao et al., 2017). (Yager, 1988) presented an aggregation method according to the OWA operation that is the generalisation of three fundamental groups of aggregation roles including (a) fuzzy sets intersection, (b) union, and (c) averaging functions. OWA is considered as a weighted sum with ordered evaluation criteria; therefore, in addition to the criterion weights, this factor is utilised to facilitate the generation of several scenarios. The order weight provides a basis for managing the level of trade-off between criteria explicitly. The trade-off degree is defined as the degree to that criterion/trade-off weights are employed in the aggregation process (Malczewski 1999). In general, the OWA approach provides an aggregation between two extreme values which are known as ANDness (pessimistic approach) and ORness (optimistic approach)(Yager, 1988).

OWA includes two types of weights associated with criteria and orders. The criterion weight indicates the level of importance for each criterion.; The weight that is assigned to a criterion map indicates that the particular criterion is assigned the same weight in all locations (Ferretti \& Pomarico, 2013; Malczewski et al., 2003). The ordered weights are indicated the significant of criterion in a location as compared with other location. In fact, ordered weights are allocated to a given location's attribute value in descending sequence regardless the attribute map from which the value comes (Malczewski, 2006). The re-ordering process includes affiliating an order weight using a specific ordered location of the weighted attribute values. The coefficients which are utilised for weighting process are not explicitly connected with a specific criterion value but rather, are allocated to an ordered location for a nominated position.

The highest order weight is allocated to the criterion with the most significant weighted values for each position, the next one is assigned to the next significant values, and this trend will be continued. Ordered weights control the weighted criteria aggregation sequence. For instance, nominated a group of attribute values at the ith position on the jth criterion, $\mathrm{C}_{\mathrm{ij}}=(0.7,0.2,0.9)$, and a group of associated order weights, $\mathrm{O}_{\mathrm{j}}=(0.3,0.2,0.1)$, the OWA process includes: (1) reordering the attribute values as follows: $r_{1 j}=0.9, r_{2 j}=0.7$, and $r_{3 j}=0.2$, and (2) combining the weighted ordered attribute values; which is defined as OWA $=(0.3 \times 0.9)+(0.2 \times 0.7)+(0.1 \times$ $0.2)=0.43$ (Drobne \& Lisec 2009; Yager 1988; Malczewski 1999). While the criterion weight indicates the level of importance of each criterion, the order weight indicates to what extent the importance of each criterion.

Clarifying OWA in the context of multi-criteria analysis indicates that OWA provides a basis to alter the attribute maps contribution from a minimum-type (logical AND) through all intermediate sets to a maximumtype (logical OR) combination (Malczewski et al., 2003). To adjust in a spatial environment, for a nominated group of $n$ criterion layers, OWA is determined as a combination of layers operates with an $i$-th position (objects) and a group of ordered weights,

$\mathrm{O}=\mathrm{O}_{1}, \mathrm{O}_{2}, \ldots, \mathrm{O}_{n}$ such that;

$\mathrm{O}_{j} \in\left[\begin{array}{ll}0 & 1\end{array}\right]$

where $\mathrm{j}=1,2, \ldots \mathrm{n}$ also

$$
\sum_{\mathrm{j}=1}^{n} \mathrm{O}_{j}=1
$$

As well as a group of criterion weight $C=\mathrm{c}_{1}, \mathrm{c}_{2}, \ldots, \mathrm{c}_{n}, \mathrm{c}_{j} \in\left[\begin{array}{ll}0 & 1]\end{array}\right]$ and

$$
\sum_{\mathrm{j}=1}^{n} \mathrm{c}_{j}=1
$$

Given the class of attribute values $\alpha_{i 1}, \alpha_{i 2}, \ldots, \alpha_{i n}$ at the $i$-th location (raster cell):

$$
\text { OWA } i=\sum_{\mathrm{j}=1}^{\mathrm{n}} u_{i} r_{i j} \quad u_{j}=\frac{o_{j} c_{j(*)}}{\sum_{\mathrm{j}=1}^{\mathrm{n}} o_{j} c_{j(*)}}
$$

According to the equation $r_{i 1} \geq r_{i 2} \geq \ldots \geq r_{i n}$ is considered as the pattern attained by reordering the attribute values $a_{i 1}, a_{i 2}, \ldots, a_{i n}$; in addition, $\mathrm{Cj}\left({ }^{*}\right)$ is the rearranged $j$ th criterion weight, $c j$. The criterion weights are arranged based on $r_{i 1} \geq r_{i 2} \geq \ldots \geq r_{i n}$ and it is important to indicate the variation among the criterion weights and the order weights. The criterion weights are allocated based on each criterion significance in order to demonstrate the trade-offs between criteria. The similar weight of $c j$ is allocated to the all positions on the $j$ th criterion map. The order weights are connected with the values of criterion on a location-by-location. They are allocated to the $i$ th location's attribute value in descending sequence regardless of from which layer the value comes. In fact, this method is considered a proper method due to the broad range of combination operators which are provided by assigning the proper ordered weights (Malczewski, 2006). The actual class of the OWA function is defined based on the form of the order weights. Various techniques have been used to determine the weights. In this research the focus is on the maximum entropy approach. The approach that uses the measure of ORness as well as the dispersion measure. According to (Yager, 1988) ORness measure is described as:

$$
\text { ORness }=\alpha=\sum_{j=1}^{\mathrm{n}} \frac{\mathrm{n}-j}{n-1} O_{j}
$$


The $\alpha$ value fluctuates between 0 to 1 and determines the level to that an OWA function, according to combination function, is same with the logical OR (MAX function). This measure is defined in the circumstance of decision-making well-established behavioural theory. Accordingly, ORness is used to measure the degree of the experts' optimism (Yager, 1988). An ORness value between 0.5 to 1 indicates optimistic decision policies, while a range less than 0.5 represents pessimistic policies. For ORness equal to 0.5 , the decision strategy is risk neutral. In fact, OWA is described by the means of the dispersion measure. Utilising Shannon's entropy measure, the normalised dispersion is explained as:

$$
\omega=-\sum_{j=1}^{\mathrm{n}} \frac{o_{j} \ln o_{j}}{\ln n}
$$

The value of $\omega$ ranges between 0 to 1 ; while the higher the equitability between the weights, the dispersion measure is higher as well. The dispersion is explained as the grade to that the OWA functions utilised the data comprised in the $n$ layers. The further dispersed the order weights, the further data is being utilised in layers combination (Malczewski, 2006). According to (O'Hagan, 1990), the application for recognising the order weight is developed employing the ORness degree and dispersion (entropy). Thus, a group of order weights is achieved using the nonlinear mathematical programming as follow:

Maximise $\omega$,

$$
\text { Where } \alpha=\sum_{j=1}^{\mathrm{n}} \frac{\mathrm{n}-j}{n-1} O_{j}, \sum_{j=1}^{\mathrm{n}} O_{j}=1,0 \leq O_{j} \leq 1 \text {, for } j=1,2, \ldots, \mathrm{n} \text {. }
$$

A measure to the issues (6) establishes the maximum dispersion degree (and trade-off) for a defined level of ORness or $\alpha$ (Malczewski, 2006).

\section{b. Study area}

Johor Bahru (JB) is the capital of Johor state situated at the southern part of Malaysia. This area is the greatest metropolitan area in Malaysia, second only to Kuala Lumpur. Johor Bahru has remarkable industrial and commercial areas, which makes the area significant in terms of economic development. Johor Bahru metropolitan area includes 220,000 hectares, $15 \%$ of which is urbanised with around $60 \%$ of land that is used for agriculture, while the rest covered by river basins and forests. Iskandar Malaysia has being developed on the basis of the Comprehensive Development Plan (CDP) in order to enhance the development of Johor Bahru (Rizzo \& Glasson, 2012). Iskandar Malaysia's population was 1.8 million in 2013 and it is estimated to accommodate 3 million inhabitants by 2025 (Http://www.irda.com.my/2015).

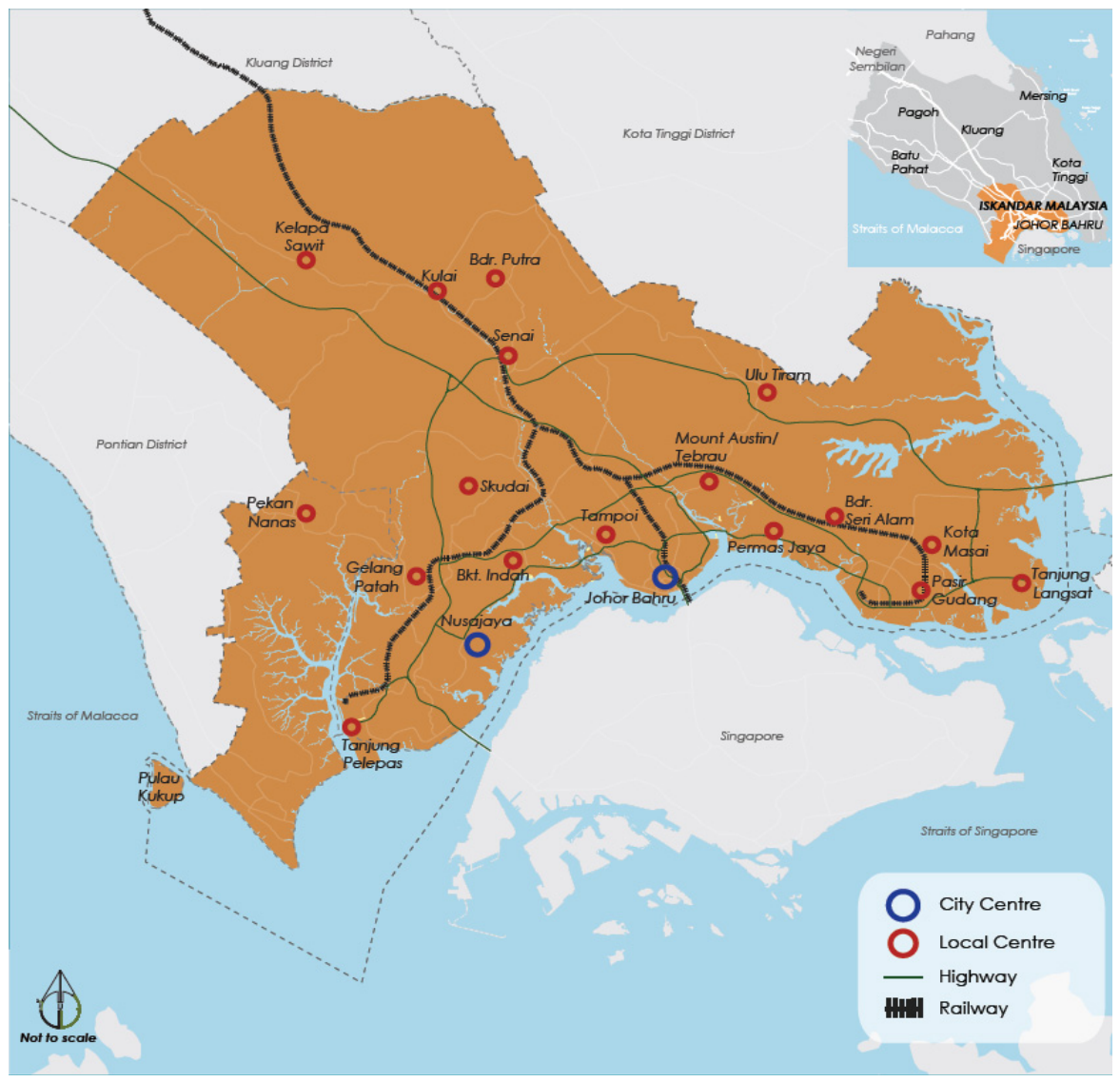

Figure 2. Iskandar Malaysia Region. Source: IRDA. 
While Malaysia, particularly Iskandar Malaysia, has not suffered natural hazards involving earthquakes, typhoons and volcano, floods have severely affected most of the residential areas (Kia et al. 2012). However, the vulnerability of facilities and infrastructure in this region has not been evaluated for current and future situations (Malalgoda et al. 2014; Khalid \& Shazwani 2015). In addition, due to the increasing frequency of high impact natural disasters, the concept of risk mitigation and resilient development needs spatial consideration. Hence, urban resilience measures in Iskandar Malaysia are crucial to address the challenges caused by flood hazard. Figure 3 indicates the methodological framework to model the flood risk assessment in Iskandar Malaysia region.

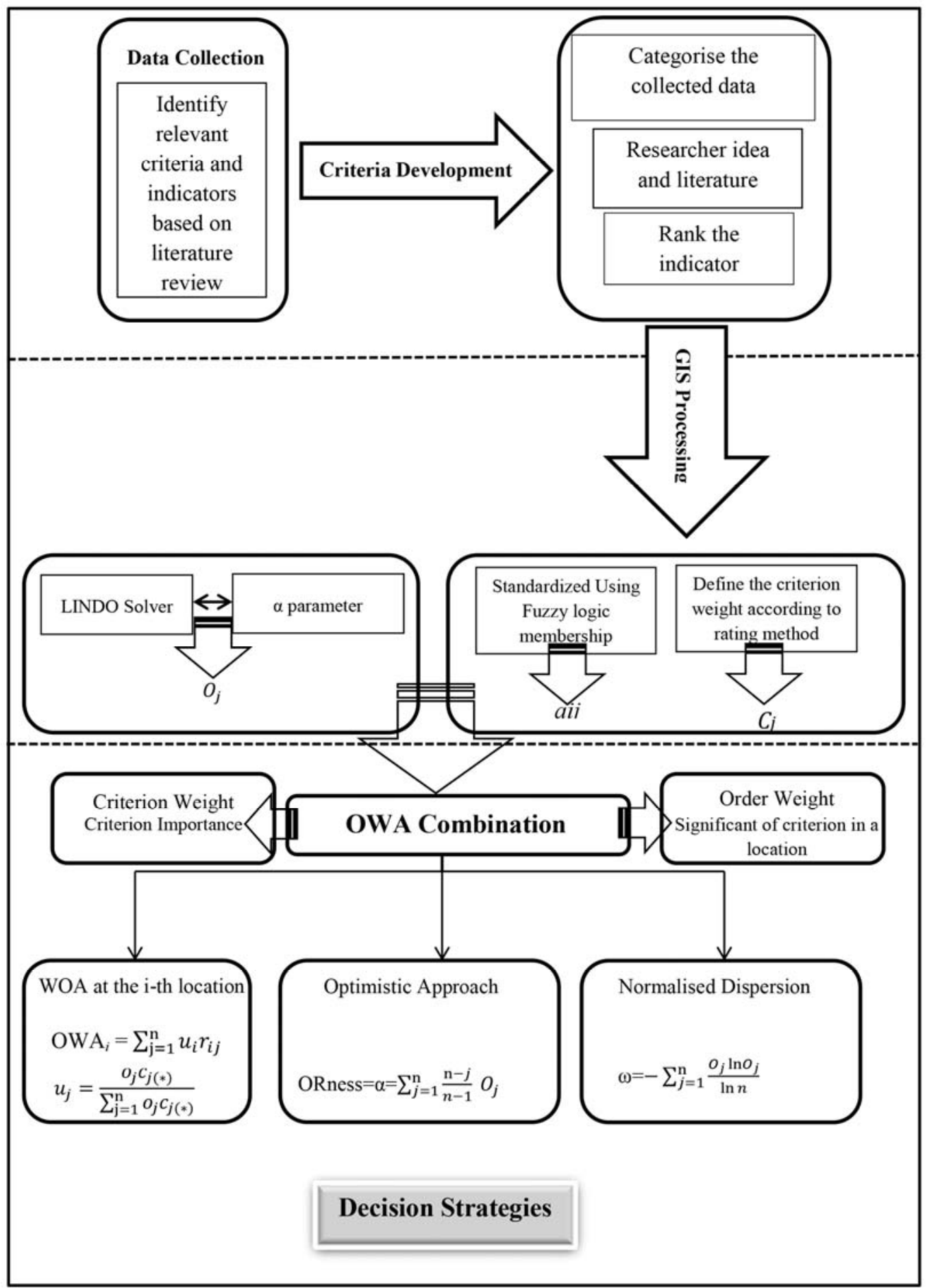

Figure 3. Structure of GIS-OWA model. 


\section{c. Criteria, indicators, and associated weights}

Conducting this research requires the criterion maps to be identified in standardised layer. According to (Malczewski 1999), three methods namely ranking, rating, and pairwise comparison, are used to assign weight to each criterion, the assigned weight must present the degree to which an expert is consenting to trade-off one criterion for another. As illustrated in Figure 3, based on the $c j$, which is known as criterion weight, the OWA incorporates the weights as well as the layers. The outcomes of standardised weighted layers are considered as the layer that is used in the OWA combination process. In the OWA process MAXness (ORness) indicator, $\alpha$ needs to be specified; the parameter is used as the material to the Solver - LINDO. The mathematical programming problem (Equation 6) is solved by using LINDO, it makes an OWA rule using a group of optimal order weights that correspond to the designated $\alpha$ parameter.

OWA combines $o j, c j$, and $a i j$, that are defined as order weights, criterion weights as well as the standardised criterion maps respectively, into a general value allocated to the location on the generated layer based on the OWA procedure (Figure 3). The developed layer presents values that have policy implications form environmental, economic, and social perspectives (Malczewski, 2006).

Physical and social indicators constitute the main criteria in this study. For physical criterion, indicators associated with natural and built environment are extracted from literature (Gangrade et al. 2019; Fernández \& Lutz 2010; Richert et al. 2011; Paquette \& Lowry 2012; Jianfen et al. 2013). For social criterion, due to the lack of information only two indicators, population density and property value, were considered. Table 1 shows the indicators, their description and the attributes that explain the vulnerability. For assigning the priority to indicator, the fuzzy membership function in a GIS environment was adopted. The fuzzy set theory (L. a. Zadeh, 1988; L. A. Zadeh, 1965) was utilised to standardization the indicators. Standardization is considered as a procedure which transfigures and rearranges the indicators and provides a basis for comparison (Gorsevski et al., 2012). Ten indicators are identified as significant factors that contribute to vulnerability. Based on the indicator's level of contribution to vulnerability, they are divided into sub-indicators. For reclassifying the indicator and demonstrating the level of importance, a rank has to be allocated to each sub-indicator according to literature and expert idea.

Table 1. Indicators for flood vulnerability assessment and their description

\begin{tabular}{|c|c|}
\hline Indicator & Description \\
\hline $\begin{array}{l}\text { Distance from } \\
\text { major stream }\end{array}$ & $\begin{array}{l}\text { Areas that are located adjacent to streams have a high risk of water overflow and water } \\
\text { velocity. Based on the records, areas which are located near to these features are most } \\
\text { affected by the consequences of flooding. } \\
\text { The distance from major stream intervals that are used in this study is identified as: a) } \\
<1000 \mathrm{~m}, \mathrm{~b} \text { ) between } 1000 \text { and } 2000 \mathrm{~m} \text {, c) between } 2000 \text { and } 5000 \mathrm{~m} \text {, and d) }>5000 \mathrm{~m} \text {. }\end{array}$ \\
\hline Elevation & $\begin{array}{l}\text { Elevation and topography influence the flow direction, size, and severity of floods } \\
\text { (Hartnett \& Nash } 2017 \text {; Fernández \& Lutz 2010; Kia et al. 2012; Azmeri et al. 2016). } \\
\text { During the flood in } 2006 \text { and } 2007 \text { within the study area, the recorded level of water } \\
\text { was around } 5 \text { meters. Thus, areas with elevation below } 5 \text { meters are considered to have } \\
\text { the highest flood vulnerability (Jianfen et al. 2013b; Paquette \& Lowry 2012; Azmeri } \\
\text { et al. 2016; Mohamed \& El-raey, 2019). } \\
\text { Three classes of elevation intervals generated from the Digital Elevation Model } \\
\text { (DEM) using a digital contour map: a) } 1 \text { to } 5 \text { meters, b) } 5 \text { to } 10 \text { meters, and c) }>10 \\
\text { meters. }\end{array}$ \\
\hline $\begin{array}{l}\text { Slope (in terms } \\
\text { of } \\
\text { velocity) }\end{array}$ & $\begin{array}{l}\text { Amount and velocity of flooding are affected by slope. Improper use of slope will have } \\
\text { adverse effects and increases losses (Fernández \& Lutz 2010; Kia et al. 2012; } \\
\text { Azmeriet al. 2016; Mohamed \& El-raey, 2019). } \\
\text { ). The slope map is generated using the DEM, and it is classified into eight classes of } \\
\text { degree, with steeper slopes causing quicker and more hazardous flow (Fernández \& } \\
\text { Lutz 2010; Kia et al. 2012): } \\
0-3,3-5,5-10,10-15,15-20,20-30,30-40,40-50 \text { and }>50 \text {. }\end{array}$ \\
\hline Land use & $\begin{array}{l}\text { Types of land use influence the vulnerability. Impervious surfaces change the natural } \\
\text { flow that can affect the risk and peak discharge (Fernández \& Lutz 2010; Paquette \& } \\
\text { Lowry 2012; Jianfen et al. 2013; Kia et al. 2012; Gangrade et al., 2019). }\end{array}$ \\
\hline Geology & $\begin{array}{l}\text { Flood occurrence relates to geological subsoil both in terms of erodability and } \\
\text { permeability. Geology has a noticeable influence on drainage capacity (Paquette \& } \\
\text { Lowry 2012; Jianfen et al. 2013; Kia et al. 2012; Richert et al. 2011; Mohamed \& El- } \\
\text { raey, 2019) }\end{array}$ \\
\hline
\end{tabular}




\begin{tabular}{|l|l|}
\hline $\begin{array}{l}\text { Distance from } \\
\text { river }\end{array}$ & $\begin{array}{l}\text { The distance from rivers is recognised as factor that influences vulnerability (Paquette } \\
\text { \& Lowry, 2012a; Wardekker, de Jong, Knoop, \& van der Sluijs, 2010). Distance } \\
\text { intervals from rivers are identified as: a) }<100 \mathrm{~m}, \mathrm{~b}) \text { between } 100 \text { and 500 m, c) } \\
\text { between 500 and } 1500 \mathrm{~m} \text {, and d) }>1500 \mathrm{~m} .\end{array}$ \\
\hline $\begin{array}{l}\text { Slope (in terms } \\
\text { of lag time) }\end{array}$ & $\begin{array}{l}\text { Water remains in flat areas for longer time thereby causing more damage (Fernández } \\
\text { \& Lutz 2010; Kia et al. 2012; Mohamed \& El-raey, 2019). }\end{array}$ \\
\hline $\begin{array}{l}\text { Distance from } \\
\text { discharge } \\
\text { channel }\end{array}$ & $\begin{array}{l}\text { Areas that are located around discharge channels can be affected during disasters time } \\
\text { (Fernández \& Lutz 2010; Kia et al. 2012). } \\
\text { The values that are adjusted to distances from discharge channels for this study are } \\
<100, \text { between 100 and 500, between 500 and 1000, and }>1000 \text { meters (Fernández \& } \\
\text { Lutz 2010; Jianfen et al. 2013). }\end{array}$ \\
\hline $\begin{array}{l}\text { Population } \\
\text { density }\end{array}$ & $\begin{array}{l}\text { Population density indicates the areas with people and asset concentration. Areas with } \\
\text { higher density are more vulnerable to flooding (Brenkert, 2010; Chang, Chang, \& } \\
\text { Chang, 2008; Paquette \& Lowry, 2012a; Röthlisberger et al., 2017; Gangrade et al., } \\
\text { 2019). }\end{array}$ \\
\hline Property value & $\begin{array}{l}\text { Flood occurrence influence different parts of the society such as infrastructure and } \\
\text { properties (Kubal, Haase, Meyer, \& Scheuer, 2009; Mendoza-tinoco et al., 2017). As } \\
\text { such, the higher the property value, the higher the vulnerability to floods. }\end{array}$ \\
\hline
\end{tabular}

A fuzzy membership type for each criterion has to be established to allocate the level of vulnerability and standardise each criterion map. Fuzzy membership type has to be chosen according to data characteristics and the ways that the data contributes to flood vulnerability. Three classes involving Fuzzy Mean-StandardDeviation Small (MS Small), Fuzzy Small, and Fuzzy Large, are utilised for assigning weightage to each criterion layer. When very small values in a criterion layer have a greater possibility of occurrence, Fuzzy MS Small is utilised. Fuzzy Large is used when larger values present a greater probability of becoming part of the data set while Fuzzy Small is used for smaller values. The operation of the fuzzy technique presents a principal for classifying the criteria along a scale of 0 to 1 . The values allocated to 0 pose no probability, while locations assigned a value of 1 present the highest probability of flood vulnerability.

Table 2 lists the indicators, fuzzy membership types and the linked weights that are utilised to generate the flood vulnerability scenarios in an Arc GIS 10.0 environment.

Table 2. Priorities of the indicators, assigned weights, and fuzzy functions.

\begin{tabular}{|l|c|c|}
\hline \multicolumn{1}{|c|}{ Criteria } & Criterion Weight & Fuzzy Function \\
\hline Distance from main stream & 16 & Small \\
\hline Elevation & 14 & MS small \\
\hline Land use & 13 & Small \\
\hline Slope (in terms of water velocity) & 12 & Small \\
\hline Geology & 11 & Small \\
\hline Land value & 10 & Large \\
\hline Population density & 8 & Large \\
\hline Distance from river & 7 & Small \\
\hline Slope (in terms of lag time) & 5 & Large \\
\hline Distance from discharge channel & 4 & Small \\
\hline
\end{tabular}

The total weight assigned to the indicators is equal to 100 . Distance from a major stream is recognised as the most significant indicator (DREF Bulletin 2007; Kia et al. 2012; Fernández \& Lutz 2010; Yeganeh \& Sabri 2014; Khalid \& Shazwani 2015; Ahmadisharaf et al. 2016).

The function of fuzzy is determined based on the description of each indicator in Table 1. A ranking method according to the previous studies and expert knowledge to identify the weightage of each indicator is also used (Yeganeh \& Sabri 2014; Kia et al. 2012; Fernández \& Lutz 2010; Lawal et al. 2014; Musungu et al. 2012; Levy et al. 2007; Ahmadisharaf et al. 2016). Table 2 shows the weights and fuzzy functions assigned to each indicator.

The order weights were assigned to generate the model according to the parameter $\alpha$ (ORness). Table 3 indicates the ordered weights $\left(\mathrm{O}_{\mathrm{n}}\right)$ that are generated in this study. 
Table 3. The order weights for selected values of the ORness $(\alpha)$.

\begin{tabular}{|c|c|c|c|c|c|c|c|}
\hline Ordered Weight & 0 & 0.1 & 0.3 & 0.5 & 0.7 & 0.9 & 1 \\
\hline $\mathrm{O}_{1}$ & 0.000 & 0.001 & 0.027 & 0.100 & 0.234 & 0.525 & 1.000 \\
\hline $\mathrm{O}_{2}$ & 0.000 & 0.001 & 0.035 & 0.100 & 0.184 & 0.250 & 0.000 \\
\hline $\mathrm{O}_{3}$ & 0.000 & 0.003 & 0.044 & 0.100 & 0.145 & 0.119 & 0.000 \\
\hline $\mathrm{O}_{4}$ & 0.000 & 0.006 & 0.056 & 0.100 & 0.114 & 0.056 & 0.000 \\
\hline $\mathrm{O}_{5}$ & 0.000 & 0.013 & 0.071 & 0.100 & 0.090 & 0.027 & 0.000 \\
\hline $\mathrm{O}_{6}$ & 0.000 & 0.027 & 0.090 & 0.100 & 0.071 & 0.013 & 0.000 \\
\hline $\mathrm{O}_{7}$ & 0.000 & 0.056 & 0.114 & 0.100 & 0.056 & 0.006 & 0.000 \\
\hline $\mathrm{O}_{8}$ & 0.000 & 0.119 & 0.145 & 0.100 & 0.044 & 0.003 & 0.000 \\
\hline $\mathrm{O}_{9}$ & 0.000 & 0.250 & 0.184 & 0.100 & 0.035 & 0.001 & 0.000 \\
\hline $\mathrm{O}_{10}$ & 1.000 & 0.525 & 0.234 & 0.100 & 0.027 & 0.001 & 0.000 \\
\hline Dispersion & 0.000 & 0.571 & 0.911 & 1.000 & 0.911 & 0.571 & 0.000 \\
\hline
\end{tabular}

\section{Results and discussion}

The purpose of conducting OWA approach is to recognise and prioritise areas with higher flood risk and vulnerability within Iskandar Malaysia. The analysis aims to generate several decision alternatives based on the experts' judgements with different levels of optimism. The goal is obtained utilising different ORness or $\alpha$ value that leads the users to generate pessimistic to optimistic strategies. Each generated policy is linked with $\alpha$ value and the dispersion measure (trade-off) among evaluation criteria. In fact, the $\alpha$ value offers continues range of pessimistic to optimistic policies to the experts (Malczewski, 2006).

Figures 4, 5, and 6 indicate seven decision alternatives; each created based on an $\alpha$ value (ORness or degree of optimism) and the dispersion (or trade-off) among evaluation criteria. The generated alternative, based on $\alpha=0$, develops a risk averse solution and demonstrates a highly pessimistic strategy. In this strategy, degree of tradeoff (dispersion) is equal to 0 . This insinuates that there is no trade-off between the criteria so it is associated with AND Boolean operators. When a probabilistic perspective is used, it means the worst scenario is defined by assigning 1 as the relevant possibility. The generated map demonstrating $\alpha$ value of 0 is allocated to each location in the region, meaning that at minimum, one criterion with 0 value exists at each location. This strategy indicates in the greatest pessimistic situation, all the locations within the region are vulnerable so no action should be taken. For instance, when the $\alpha$ value is equal to 0 , due to the criterion with 0 value at each location all the locations within the Iskandar region have high level of vulnerability. Increasing $\alpha$ value from 0 to 0.1 , 0.3 , and 0.5 is in-line with increasing the degree of optimism and trade-off between evaluation criteria. By increasing the $\alpha$ value, areas with higher vulnerability can be determined easily and the larger areas can be considered for development. Most of the districts within the region have high level of vulnerability while $\alpha$ value denotes pessimistic strategies. By increasing the level of optimism southern districts Tebrau, Plenton, JB, and Pulai still have high level of vulnerability (Figure $4, \alpha=0.1,0.3$, and 0.5 ). 

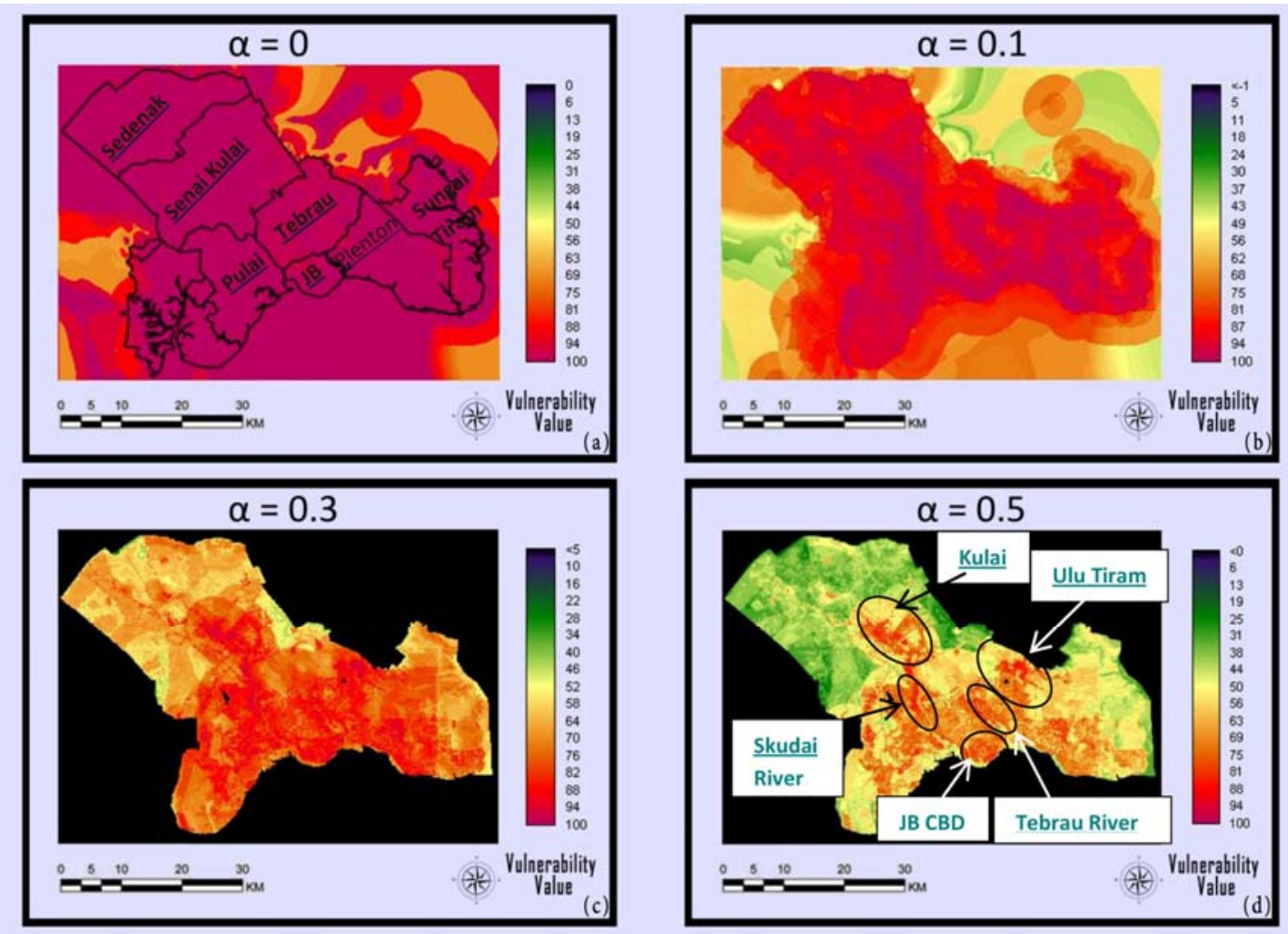

Figure 4. Decision strategies for Iskandar Malaysia ( $\alpha$ values show the Pessimistic to Neutral Alternative)

The strategy map that evaluates vulnerability with an $\alpha=0.5$ indicates neutral approach. As such, it is expected that the outcome map where $\alpha=0.5$ being similar to the result of WLC that was generated in other studies for the same region (Yeganeh \& Sabri, 2014) (Figure 5).
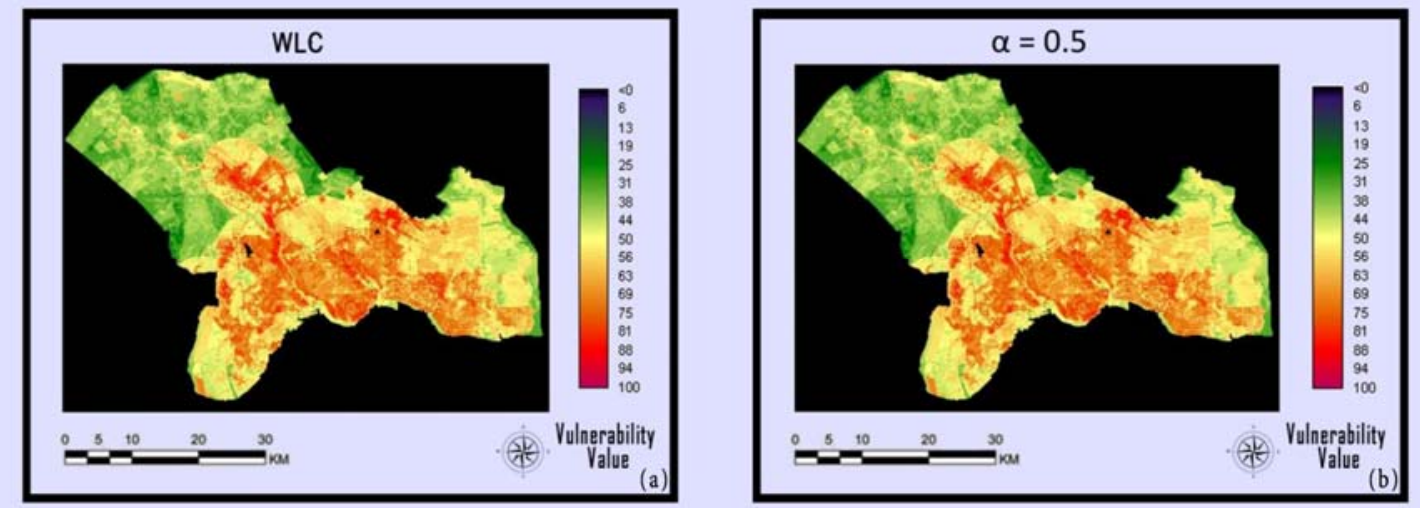

Figure 5. Comparison of WLC and OWA ( $\alpha=0.5)$.

Increasing the $\alpha$ value from 0.5 to 1 enhances the level of optimism and decreases the trade-off level between criteria. This set of ordered weight generates larger areas with less vulnerability as can be seen in Figure 6 . 


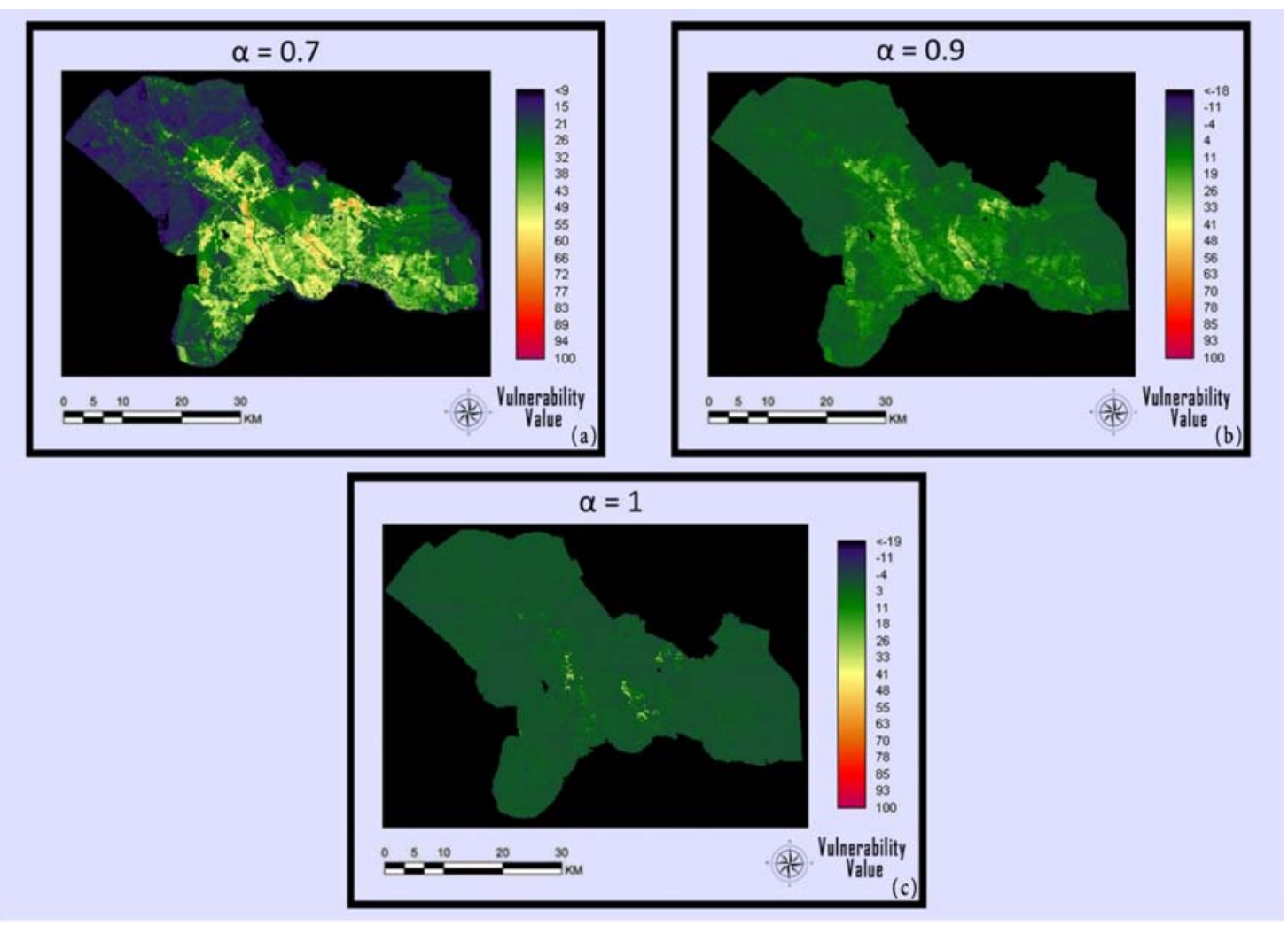

Figure 6. Decision strategies for Iskandar Malaysia (Neutral to Optimistic alternatives).

Figure 7 illustrates the locations in the region that were influenced by the recent floods. The comparison of results from optimistic and pessimistic strategies that were obtained from OWA model, and real flood situations indicates that pessimistic strategies $(\alpha=0.1$ and 0.3$)$ highlight the areas that are influenced by previous floods with higher probability values $(>69 \%)$. However, in optimistic strategies $(\alpha=0.7,0.9$, and 1$)$, areas that were previously affected by floods considered as moderate to low risk with probability values of $11 \%$ to $55 \%$. This proves the validity of the range of pessimistic strategies generated in this study. In the most pessimistic strategy, the entire region is considered to be vulnerable with the highest level of vulnerability. However, the possibility of flood occurrence in areas such as Sedenak, Sungai Tiram and Plentong is low according to real flood occurrence records. On the other hand, based on optimistic strategy $(\alpha=1)$, in most of the areas in the region except the areas that are located near to the river, are considered to have low level of flood risk some areas have been affected by flood (Figure 7). In optimistic views, areas in close proximity to the river are still considered to be vulnerable (the map in figure 6 indicates a possibility of $40 \%$ of risk). Thus, these areas need attention in terms of development plans, land use regulation, and human activities, specifically when it comes to further development. Surprisingly, the flooded area around Ramsar Site annotated in Figure 7 is not highlighted as significantly vulnerable in the OWA maps generated. A possible reason for that is the impact of other criteria such as population density, property value, and land use. In fact, in the absence of above mentioned criteria in Ramsar Site due to the environmental conservation, flood vulnerability in this site has been less affected as compared to others. 


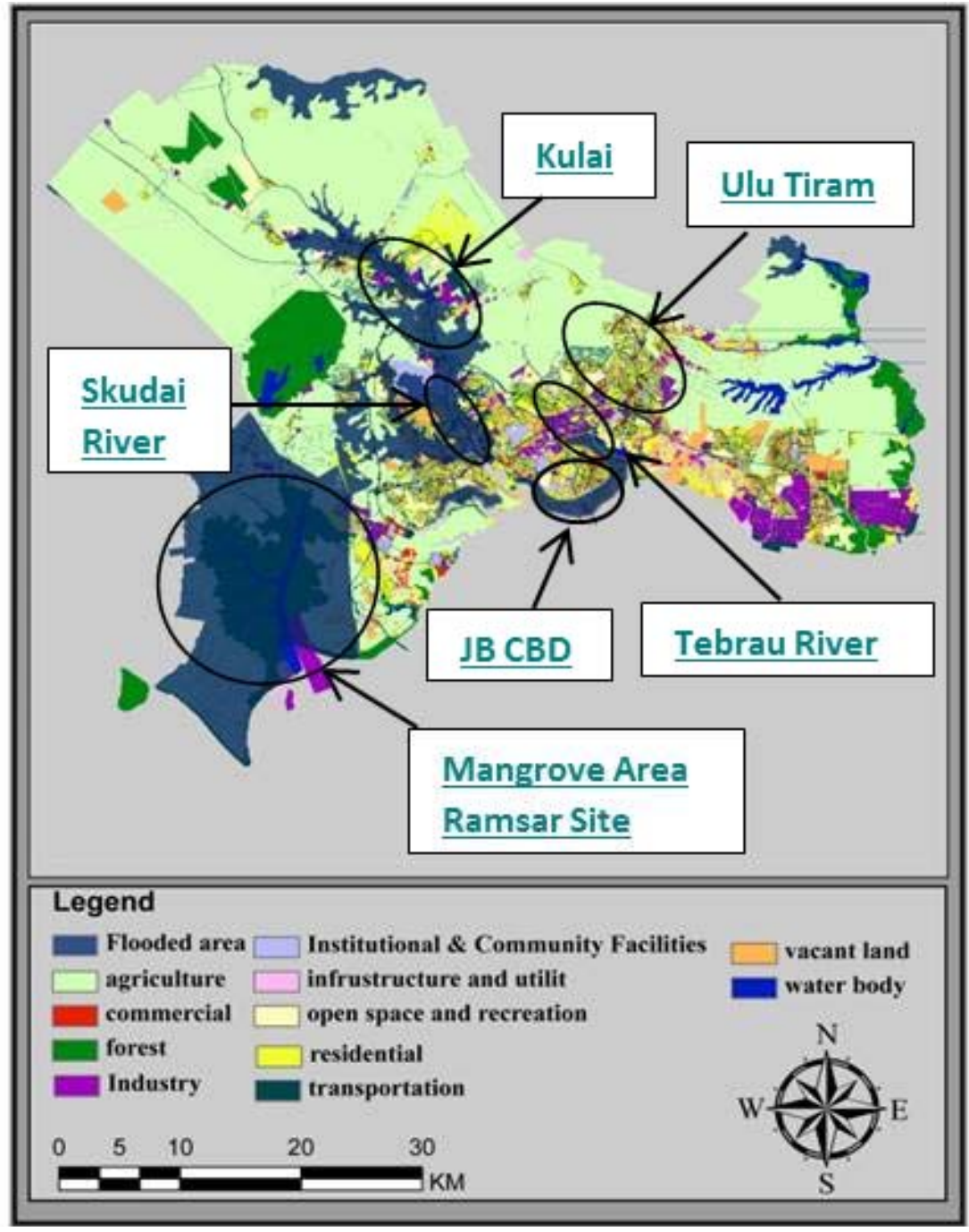

Figure 7. Flooded area within the Iskandar Malaysia in 2012. Source: (Yeganeh \& Sabri, 2014).

In conclusion, from the results illustrated in Figures 4, 5, and 6, the maps with $\alpha$ values between 0.3 and 0.7 were selected for further discussion. These maps are able to better explain the vulnerability of the area in the range of optimistic and pessimistic strategies.

Evaluating the risk of flood disaster based on current developments within the region according to pessimistic strategy $(\alpha=0.3)$ indicates that almost all built up areas with high population density are considered as high vulnerability. These areas are more vulnerable because the value of property is higher than the northern parts (Kubal et al. 2009). This is the reason for the intensity of probability values, which are above $76 \%$ in areas around Johor Bahru (JB), where is the urban centre with higher population density and more built up areas. In the northern parts, where the land use is mostly forest or used for agriculture (Figure 2), there is comparatively less vulnerability; the probability of vulnerability between $50 \%$ and $70 \%$, except where the mainstreams and rivers exist, thus confirming the argument of Paquette and Lowry (2012) that these types of land use will reduce the risk of flood hazard. Tebrau River, that is situated at the Eastern parts of the Iskanda Malaysia, has an obvious impact on the level of vulnerability, which is higher, as can be seen in this map (Figure 4).

The impact of built up areas can be observed in the map generated with an $\alpha$ value of 0.5 . The probability values are higher than $70 \%$ around road networks and urbanised areas. These built up areas will decrease permeability, resulting in higher flood risk (Kia et al. 2012; Richert et al. 2011). Although less pessimistic, this map highlights the most vulnerable areas around places with high population density and rivers in the region such as JB CBD, Kulai, Ulu Tiram, Skudai River, and Tebrau River (Figure 4).

The results obtained from an optimistic map $(\alpha=0.7)$ also indicate the flood vulnerability in urbanised areas as well as settlements in close proximity to the rivers and water bodies, although with moderate level of significance (Paquette \& Lowry 2012; Jianfen et al. 2013; Kia et al. 2012) (Figure 7). As expected, comparing the land uses in Figure 2 and the results of OWA generated maps (Figures 4, 5, and 6) indicate that the combination of settlement and infrastructure developments near to rivers such as Tebrau and Skudai, increases 
the level of risk and the vulnerability. The generated maps also indicate that, the impact of other physical criteria such as elevation, slope (water velocity and time), distance to discharge channel and geology will be more significant when combined with population density and built up areas around the main stream and rivers. Hence, it is imperative that a reasonable distance from water bodies and main streams to the areas with higher population densities and built up areas will reduce the vulnerability and needs to be considered in future developments.

Iskandar Malaysia is one of the vulnerable areas due to flood hazards associated with its location, population density and development. In this study we evaluated the proposed development plan of Iskandar Malaysia for 2025 (Figure 8) using the optimistic and pessimistic strategies to highlight the most vulnerable and resilient areas of Iskandar Malaysia for the next 8 years. Apparently, assessing flood hazard according to WLC ignores the uncertainty of future risks. Thus, generating several scenarios that may affect the region should be noted as crucial matter for developing a resilient region. In general, the comprehensive plan suggested that during 2011 and 2025 the proportion of built up areas including road networks, residential, commercial, and industrial land uses will increase from $45 \%$ up to $78 \%$. Accordingly, the proportion of non-built up areas will decrease from $55 \%$ to $23 \%$. One of the major land use changes is agricultural that will be replaced by residential, commercial and industrial land uses. This land use change will cause changes in hydrological cycle as a result of more impervious surfaces (Paquette \& Lowry 2012; Jianfen et al. 2013; Kia et al. 2012; Richert et al. 2011).

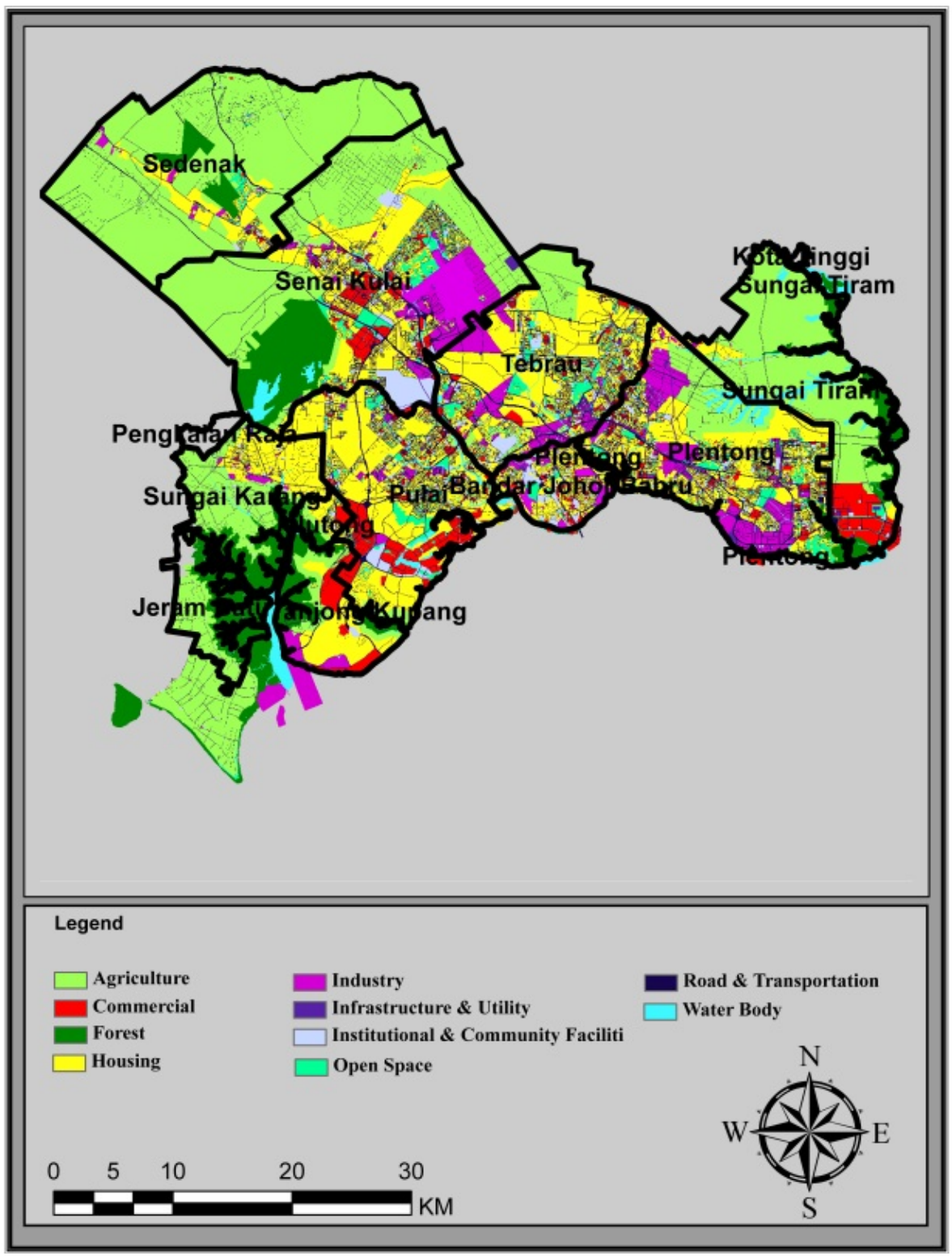

Figure 8. Proposed development plan of Iskandar Malaysia 2025. 
To be specific, based on the proposed plan, in Pulai and Tebrau districts, most of the agricultural lands are considered to be converted to residential and commercial land uses, where distance to rivers and main streams is still a remaining as a remarkable issue. According to the pessimistic strategy $\alpha=0.3$ (Figure 9), these districts will have higher levels of vulnerability. It means that by replacing agriculture land with residential and commercial land uses, particularly in areas close to Tebrau and Skudai rivers, there will be more infrastructure development, higher population density, with a rise in property values. All things considered, the future plan with suggested changes will increase vulnerability to flood in these districts.

The result of the pessimistic strategy is confirmed with the optimistic map as well. The evaluation of the proposed plan for 2025 according to the optimistic strategy $(\alpha=0.7)$ demonstrated that Pulai and Tebrau districts are among the higher vulnerable areas, with an increased probability for developments or built up areas $(55 \%$ $72 \%$ ) adjacent to main streams and rivers (Figure 10). It is evident that less vulnerability can be assumed in the northern part of Tebrau which is dominated by agricultural land uses. The impact of changing agriculture land to residential and commercial is very significant because it reduces the resilience of future developments in Iskandar Malaysia.

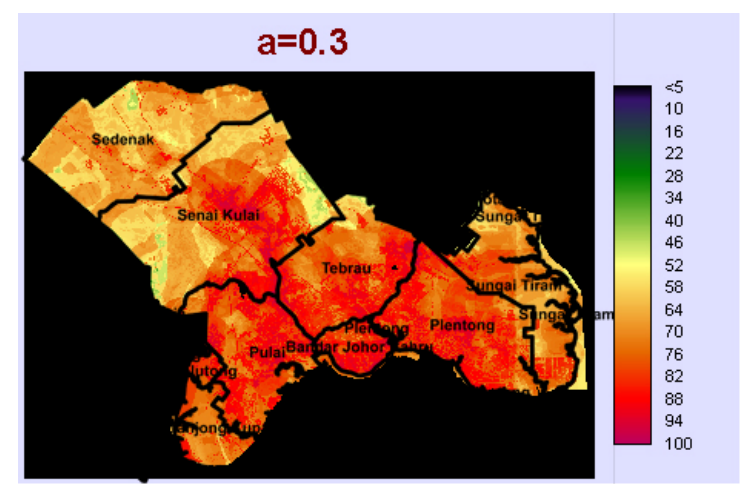

Figure 9. Pessimistic strategy.

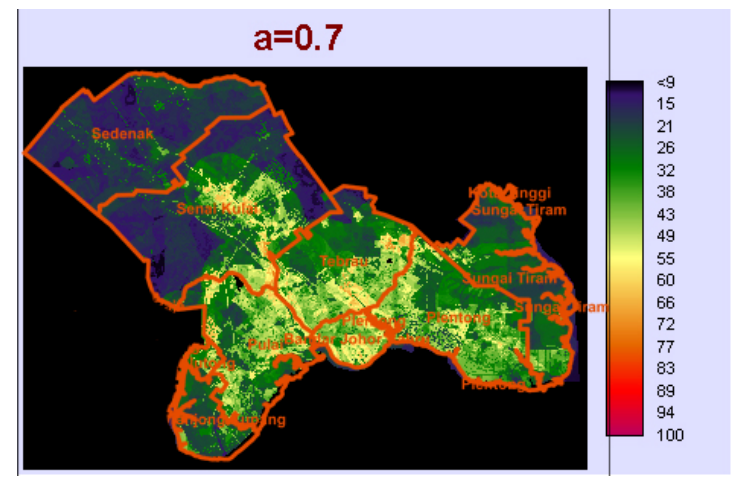

Figure 10. Optimistic strategy.

\section{Conclusion}

This research set to explore the adoption of a linguistically aggregated method, called parameterised-OWA approach as a basis for incorporating GIS and multi-criteria decision analysis to assess current and future development. The research evaluated the flood risk and vulnerability of Iskandar Malayisa. This study has also determined the criteria that influenced the vulnerability for flood in same area.

The research found that environmental, social, and economic criteria influenced the level of flood risk, vulnerability, and the resilience within the region. The combination of settlements and infrastructure developments near to rivers increased the level of vulnerability and the impact of other physical criteria. Despite the evidence of severe flooding around the mangrove areas in the Iskandar Malaysia, the urbanised regions are more vulnerable to flooding due to increasing infrastructure, higher population density and higher property value. The validity of findings in the study was confirmed by evaluating several criteria, including social and physical constructs in a range of pessimistic and optimistic strategies. As such, this research ascertained the effectiveness of coupling the multi-criteria evaluation and OWA in a GIS environment to assess the various criteria associated with flood risk, vulnerability and urban resilience. The parameterised-OWA method provided a basis to generate various decision strategies to be assessed in order to help urban planners and decision makers understand the impact of their decisions based on risk and trade-off scenarios. The obtained results indicate that the adopted methodological approach is useful in demonstrating a range of strategies that can generate 
differences of geographical locations for a better decision making process. This contrasts conventional methods that came up with a single optimal result.

In terms of policy implications, information obtained from Iskandar Regional Development Authority (IRDA) indicates that by 2025 the population will increase from 1.8 to 3 million. This in turn will lead to a higher population density as well as intensification of assets, properties and infrastructure within the region. The results of this study indicated that changes in vegetated land uses, increasing impervious surfaces as well as higher population density, especially in close proximity to rivers and water streams not only increases the flood risk and vulnerability of residents in this area, but also influences the level of resilience within the region. Thus, revisiting the development types, locations and critical measures to increase the level of resilience in Iskandar Malaysia are likely to be crucial strategies for future development.

Ultimately, the results of this study could have been improved if more data with detailed information and in higher resolution was accessible. Availability of information such as building type (e.g. single story, double story, and apartment), building footprint, age, and materials, and also socio-economic conditions (e.g. family size, and age cohorts) could further enhance our understanding on the level of flood vulnerability in the study area. Further research needs to be conducted to incorporate the results of each scenario in a simulation model to indicate the temporal and spatial impact of pessimistic and optimistic strategies.

\section{References}

[1] Azmeri, Hadihardaja IK, Vadiya R. Identification of flash flood hazard zones in mountainous small watershed of Aceh Besar Regency, Aceh Province, Indonesia. Egypt J Remote Sens Sp Sci. 2016;19(1):143-60.

[2] Röthlisberger V, Zischg AP, Keiler M. Science of the Total Environment Identifying spatial clusters of flood exposure to support decision making in risk management. Sci Total Environ. 2017; 598:593-603.

[3] Mendoza-tinoco D, Guan D, Zeng Z, Xia Y, Serrano A. Flood footprint of the 2007 floods in the UK : The case of the Yorkshire and The Humber region. J Clean Prod. 2017; 168:655-67.

[4] Hartnett M, Nash S. High-resolution flood modeling of urban areas using MSN Flood. Water Sci Eng. 2017;10(3):175-83.

[5] Ahmadisharaf E, Kalyanapu AJ, Chung E. Spatial probabilistic multi-criteria decision making for assessment of flood management alternatives. J Hydrol. 2016;533:365-78.

[6] DREF Bulletin. MALAYSIA : FLOODS. Int Fed Red Cross Red Crescent Soc. 2007;(July):1-7.

[7] Musungu K, Motala S, Smit J. Using Multi-criteria Evaluation and GIS for Flood Risk Analysis in Informal Settlements of Cape Town : The Case of Graveyard Pond. South African J Geomatics. 2012;1(1):77-91.

[8] Berkes F. Understanding uncertainty and reducing vulnerability: Lessons from resilience thinking. Nat Hazards. 2007; 41(2): $283-95$.

[9] Brooks N. Vulnerability, risk and adaptation : A conceptual framework. Tyndall Cent Clim Chang Res. 2003; 38: 1-16.

[10] Chang H and Franczyk J. Climate Change, Land-Use Change, and Floods: Toward an Integrated Assessment. Geogr Compass. 2008; 5(2): 1549-79.

[11] Chelleri L, Waters JJ, Olazabal M and Minucci G. Resilience trade-offs: addressing multiple scales and temporal aspects of urban resilience. Environ Urban. 2015; 27(1): 181-98.

[12] Chen W., Wang X., Deng Sh., Liu Ch., Xie H., Zhu Y., 'Integrated urban fl ood vulnerability assessment using local spatial dependence-based probabilistic approach', Journal of Hydrology. 2019; 575,pp. 454-469. doi: 10.1016/j.jhydrol.2019.05.043.

[13] Chowdhury S and Al-Zahrani M. Fuzzy synthetic evaluation of treated wastewater reuse for agriculture. Environ Dev Sustain. 2014; 16(3): 521-38

[14] Cohen O, Leykin D, Lahad M, Goldberg A and Aharonson-Daniel L. The conjoint community resiliency assessment measure as a baseline for profiling and predicting community resilience for emergencies. Technol Forecast Soc Change 2013; 80(9): 1732-41.

[15] Desouza KC and Flanery TH. Designing, planning, and managing resilient cities: A conceptual framework. Cities 2013; 35: 89-99.

[16] Dorasamy M, Raman M and Kaliannan M. Knowledge management systems in support of disasters management: A two decade review. Technol Forecast Soc Change 2013; 80(9): 1834-53.

[17] Drobne S and Lisec A. Multi-attribute Decision Analysis in GIS : Weighted Linear Combination and Ordered Weighted Averaging. Informatica. 2009; 33: 459-74.

[18] Fernández DS and Lutz M. Urban flood hazard zoning in Tucumán Province, Argentina, using GIS and multicriteria decision analysis. Eng Geol. 2010; 111: 90-8.

[19] Ferretti V and Pomarico S. Ecological land suitability analysis through spatial indicators: An application of the Analytic Network Process technique and Ordered Weighted Average approach. Ecol Indic 2013; 34: 507-19.

[20] Gangrade S., Kao Sh., Dullo T T, Kalyanapu A.J, Preston B.L, 'Ensemble-based flood vulnerability assessment for probable maximum $\mathrm{fl}$ ood in a changing environment, Journal of Hydrology. 2019: 576(May), pp. 342-355. doi: 10.1016/j.jhydrol.2019.06.027.

[21] Godschalk DR. Urban Hazard Mitigation: Creating Resilient Cities. Nat Hazards Rev. 2003; 4: 136-43.

[22] Gorsevski P V., Donevska KR, Mitrovski CD and Frizado JP. Integrating multi-criteria evaluation techniques with geographic information systems for landfill site selection: A case study using ordered weighted average. Waste Manag 2012; 32(2): 287-96.

[23] Harrison CG and Williams PR. A systems approach to natural disaster resilience. Simul Model Pract Theory 2016; 1-21.

[24] Ibarrara'n ME, Malone EL and Brenkert AL. Climate change vulnerability and resilience: current status and trends for Mexico. Environ Dev Sustain. 2010; 12: 365-88.

[25] Iskandar Regional Development Authority (IRDA). Facts \& Figures. www.iskandar.asia/iskandar-malaysia/facts-and-figures (2016, accessed October 2019).

[26] Isunju JB, Orach CG and Kemp J. Community-level adaptation to minimize vulnerability and exploit opportunities in Kampala's wetlands. Environ Urban. 2016; 28(2): 475-94.

[27] Jianfen L, Xingnan Z and Huimin W. Flood Risk Mapping for Different Landuse Senarios Based on RS and GIS. Appl Mech Mater. 2013; 298: 2415-9.

[28] Khalid MSB and Shazwani BS. Flood Disaster Management in Malaysia: An Evaluation of the Effectiveness Flood Delivery System. Int J Soc Sci Humanit 2015; 5(4): 398-402.

[29] Kia MB, Pirasteh S, Pradhan B, Mahmud AR, Sulaiman W and Moradi A. An artificial neural network model for flood simulation using GIS: Johor River Basin, Malaysia. Environ Earth Sci 2012; 67(1): 251-64.

[30] Kubal C, Haase D, Meyer V and Scheuer S. Integrated urban flood risk assessment - adapting a multicriteria approach to a city. Nat Hazards Earth Syst Sci. 2009; 9: 1881-95. 
[31] Kulawiak M and Lubniewski Z. SafeCity- A GIS-based tool profiled for supporting decision making in urban development and infrastructure protection. Technol Forecast Soc Change 2013; 89: 174-87.

[32] Lawal DU, Matori AN, Yusof KW, Hashim AM, Aminu M, Sabri S, et al. group-based decision support for flood hazard forecasting: A geospatial technology-based group analytic hierarchy process approach. Res J Appl Sci Eng Technol. 2014; 7(23): 4838-50.

[33] Levy JK and Hall ÆJ. Advances in flood risk management under uncertainty. Stoch Env Res Risk Assess. 2005; 19: 375-7.

[34] Malalgoda C, Amaratunga D and Haigh R. Challenges in Creating a Disaster Resilient Built Environment. Procedia Econ Financ 2014; 18: $736-44$.

[35] Malczewski J, Chapman T, Flegel C, Walters D, Shrubsole D and Healy M. GIS multicriteria evaluation with ordered weighted averaging (OWA): Case study of developing watershed management strategies. Environ Plan A. 2003; 35: 1769-84.

[36] Malczewski J. GIS and Multicriteria Decision Analysis. New York: JohnWiley, 1999, p.233.

[37] Malczewski J. Ordered weighted averaging with fuzzy quantifiers: GIS-based multicriteria evaluation for land-use suitability analysis. Int J Appl Earth Obs Geoinf. 2006; 8(4): 270-7.

[38] Manyena SB, O'Brien G, O'Keefe, P and Rose J. Disaster resilience: a bounce back or bounce forward ability? Local Environ. 2011; 16(5): 417-24.

[39] Mohamed S. A., and El-raey, M. E. 'Vulnerability assessment for flash floods using GIS spatial modeling and remotely sensed data in El Arish City, North', Natural Hazards. 2019. doi: 10.1007/s11069-019-03571-x.

[40] O’Hagan. A fuzzy neuron based upon maximum entropy ordered weighted averaging, Yager, R.R. and Zadeh LA, editor. Uncertainty in Knowledge Bases. Berlin: Springer-Verlag; 1991; 598-609.

[41] Liao, J. et al. 'Assessment of urbanization-induced ecological risks in an area with significant ecosystem services based on land use / cover change scenarios', International Journal of Sustainable Development \& World Ecology. Taylor \& Francis, 2017, pp. 1-10. doi: 10.1080/13504509.2017.1415234.

[42] Paquette J, Lowry J. Flood hazard modelling and risk assessment in the Nadi River Basin, Fiji, using GIS and MCDA. South Pacific J Nat Appl Sci. 2012; 30: 33-43.

[43] Richert E, Bianchin S, Heilmeier H, Merta M and Seidler C. A method for linking results from an evaluation of land use scenarios from the viewpoint of flood prevention and nature conservation. Landsc Urban Plan 2011; 103(2): 118-28.

[44] Rizzo A and Glasson J. Iskandar Malaysia. Cities 2012; 29(6): 417-27.

[45] United Nation Office for Disaster Reduction (UNSIDR). Anuual report. 2015.

[46] United Nation Office for Disaster Reduction (UNSIDR). Strategic Framework 2016.

[47] United Nation Office for Disaster Reduction (UNSIDR). Technological Forecasting and Social Author Information Pack. UNISDR. $2014 ; 1-12$.

[48] Usamah M, Handmer J, Mitchell D and Ahmed I. Can the vulnerable be resilient? Co-existence of vulnerability and disaster resilience: Informal settlements in the Philippines. Int J Disaster Risk Reduct 2014; 10: 178-89.

[49] Wardekker JA, Jong AD, Knoop JM and Sluijs JP. Operationalising a resilience approach to adapting an urban delta to uncertain climate changes. Technol Forecast Soc Change 2010; 77(6): 987-98.

[50] Yager RR. On ordered weighted averaging aggregation operators in multi-criteria decision making. IEEE Trans Syst Man Cybern; 1988; 18: 183-90.

[51] Yeganeh N and Sabri S. Flood Vulnerability Assessment in Iskandar Malaysia Using Multi-criteria Evaluation and Fuzzy Logic. Res J Appl Sci Eng Technol. 2014; 8(16): 1794-806.

[52] Zadeh LA. Fuzzy logic. Computer 1988; 21(4): 83-93.

[53] Zadeh LA. Fuzzy Sets. Informat Control. 1965; 8: 338-53. 